\title{
Mulemba
}

Revista Angolana de Ciências Sociais

6 (12) | 2016

Sobre a sociedade e a cultura em Angola e alhures:

algumas reflexões de percepções sobre a realidade e múltiplas experiências

\section{Os grandes desafios dos governos africanos para o século XXI}

The great challenges of African governments for the 21st century

\section{Miguel Domingos Bembe}

\section{(2) OpenEdition \\ Journals}

\section{Edição electrónica}

URL: https://journals.openedition.org/mulemba/805

DOI: $10.4000 /$ mulemba.805

ISSN: 2520-0305

\section{Editora}

Edições Pedago

Edição impressa

Data de publição: 1 novembro 2016

Paginação: $73-90$

ISSN: 2182-6471

Refêrencia eletrónica

Miguel Domingos Bembe, «Os grandes desafios dos governos africanos para o século XXI», Mulemba [Online], 6 (12) | 2016, posto online no dia 30 setembro 2018, consultado o 07 dezembro 2022. URL: http://journals.openedition.org/mulemba/805 ; DOI: https://doi.org/10.4000/mulemba.805 


\title{
Os grandes desafios dos governos africanos para o século $\mathrm{XXI}^{*}$
}

\author{
Miguel Domingos Bembe B** $^{* *}$
}

\begin{abstract}
Resumo: O sistema de governação de muitos países africanos é ainda caracterizado por um total desrespeito pelos direitos humanos, assim como pela marginalização da grande maioria dos seus povos. Neste contexto, Mbeki (2001), Mkapa (2001), Wade (2002), entre outros, consideram que a transformação estrutural e sistémica da África passa pela construção de sociedades mais abertas, mais democráticas, mais transparentes, mais participativas e mais justas. Todavia, Fátima Roque (2005; 2012), sustenta que o sucesso da transformação de África depende da superação dos obstáculos de pobreza extrema, exclusão social e analfabetismo; frágil harmonia social, política e militar; corrupção, abuso de poder e clientelismo; fracas estruturas políticas e sociedades civis pouco desenvolvidas; discriminação de género, de classes e entre a cidade e meio rural; infra-estruturas debilitadas; falta de quadros, especializações e motivações; desemprego estrutural e demasiada dependência do sector público; dívidas externas insustentáveis e problemas nas contas de capital.

Neste contexto, o presente artigo pretende identificar e caracterizar os vectores considerados essenciais para que os estados africanos enfrentem com segurança e êxito os múltiplos desafios políticos, sociais e económicos colocados aos seus governos no século xxI, baseando-se, sobretudo, na Nova Parceria para o Desenvolvimento Sustentado de África (NEPAD) (2001), ${ }^{\mathbf{1}}$ assim como na
\end{abstract}

* Este texto foi inicialmente preparado para ser apresentado no vi Colóquio de Ciências Sociais: Os desafios da sociedade angolana no século XxI. População, dinâmicas sociais e fluxos migratórios, organizado pela Faculdade de Ciências Sociais (FCS) da Universidade Agostinho Neto (UAN), em Luanda, nos dias 25 e 26 de Outubro de 2016. Impossibilitado de estar presente por razões de calendário, o mesmo foi repensado e revisto e é publicado aqui a pedido do Editor, que muito agradecemos.

** Politólogo, especialista em Estratégia. Professor Auxiliar no Departamento de Ciência Política (DCP) da Faculdade de Ciências Sociais da Universidade Agostinho Neto (FCS-UAN) e Investigador do Centro de Investigação em Análise de Políticas e Sistemas Eleitorais (CIAPSE-FCS-UAN), em Luanda e do Centro de Administração e Políticas Públicas (CAPP-ISCSP-Universidade de Lisboa), em Lisboa, Portugal. É Conselheiro do quadro de pessoal da carreira diplomática do Ministério das Relações Exteriores (MIREX), desempenhando as funções de Consultor no Gabinete do Ministro (GMRE), em Luanda, Angola.

1 New Partnership for Africa's Development (NEPAD). 
Agenda de Desenvolvimento Sustentável (2030), incluindo os seus Objectivos de Desenvolvimento Sustentável (ODs) (2015) ${ }^{\mathbf{2}}$ na Agenda 2063, assim como as sete (7) ambições africanas para a transformação estrutural do continente (2015) e no Mecanismo Africano de Avaliação pelos Pares (APRM) (2002).

Palavras-chave: África, desafios, Agendas 2030 e 2063, NEPAD, transformação sustentada, século XXI.

\section{Nota introdutória}

Reflectir sobre um continente tão heterogéneo como o africano e tentar analisar aspectos tão diversos como o socio-cultural, o político, o institucional e o económico, com as respectivas discriminações, assimetrias e ênfases, afigura-se-nos uma tarefa definitivamente gigantesca e cansativa, senão mesmo, muitas vezes difícil e até impossível.

Sem necessidade de catalogar o excessivo número de autores que se dedicam ao estudo de África, porque cansativo e por não ser o espaço adequado para o fazer, parece-nos pertinente reconhecer a existência de alguns quantos estudos desenvolvidos por africanos e analistas oriundos de outros lugares, que analisam a realidade do continente africano.

Como sublinha a economista luso-angolana Fátima Roque, no livro África, a NEPAD e o futuro, editado em 2012, alguns desses estudos enfatizam a deterioração em muitos dos países que constituem este continente, dos indicadores de desenvolvimento humano, económico, financeiro, institucional e sectorial, ao mesmo tempo que evidenciam o comportamento deficiente de determinadas variáveis qualitativas relacionadas com a paz, a reconciliação, a legitimidade democrática e a governabilidade política, a desigualdade e a discriminação (RoQUE 2012: 25-26).

Ao referirem-se aos factores endógenos e exógenos que estão na base da problemática da pobreza, do atraso e da marginalização de África, da exclusão social e da discriminação da maioria das suas populações, os antigos presidentes sul-africano e tanzaniano Thabo Mbeki (nascido em Junho de 1942) e Benjamim Mkapa (nascido em Novembro de 1938) consideraram durante o Fórum Económico Mundial realizado em Davos, em 2001, que os conflitos armados, os movimentos migratórios, a falta de humanismo, a corrupção e a

2 Transforming our World: the 2030 Agenda for Sustainable Development (The 17 Sustainable Development Goals and 169 targets of this new universal Agenda). 
incompetência de muitas lideranças africanas têm contribuído, em parte, para despoletar as crises contínuas e manter o subdesenvolvimento em que a maioria dos países e povos se encontra (Mbeki e Mkapa, apud Roque 2005: 22).

Entretanto, numa outra obra intitulada $O$ desenvolvimento do continente africano na era da mundialização, editada em 2005, Fátima Roque considera que papel igual deve ser atribuído à escravatura, à cobiça internacional, aos jogos de poder, à exploração, à manipulação de governos e das multinacionais, ao comércio corrupto de armas e à atribuição de comissões avultadas para a manutenção de negócios duvidosos (RoQue 2005: 21; ver igualmente 2012: 26).

Neste contexto, Maria José Rezende considera necessário que sejam ultrapassados os obstáculos que tardam a efectivação da democracia na maioria dos países africanos, que se constituem como um dos factores que fragilizam os estados nacionais do continente, que obstaculizam a promoção e a gestão do «desenvolvimento social $e$ humano» e impedem o sucesso do "processo construtivo de instituições capazes de fixar procedimentos voltados para os interesses colectivos [dos seus povos]» (REzENDE 2008: 101).

Em síntese, e pautando-nos nessa linha de pensamento e nas propostas de Roque, encontramos pelo menos sete (7) características que são comuns aos países africanos envolvidos em conflitos ou em situação recente de reconstrução pós-conflito:

1. Deterioração dos indicadores sociais e crescente desigualdade na distribuição dos rendimentos, da riqueza e das oportunidades;

2. Défice fiscal elevado e grave desequilíbrio na balança de pagamentos;

3. Descoordenada e insustentável dívida externa e serviço da dívida;

4. Inflação elevada e controlo ineficiente das despesas públicas, com despesas importantes não incluídas no orçamento e com desfasamento nas contas fiscais;

5. Quase total destruição das infra-estruturas físicas e sociais;

6. Sérias rupturas no mercado e desagregação regional e provincial;

7. Total desconfiança nas reformas económicas e insatisfação generalizada com a corrupção ao nível do Estado, do Governo e das Forças Armadas (RoQue 2005: 23).

Por conseguinte, a insatisfação e frustração sentidas por muitos africanos em relação aos líderes políticos e económicos por estes terem sido incapazes de encontrar respostas adequadas aos problemas 
estruturais que os afectam, tornam urgente transformar África de forma que sejam construídas sociedades mais democráticas, participativas, representativas, inclusivas, justas, desenvolvidas e pacíficas.

\section{Desafios dos governos africanos para o século XXI}

Parece-nos, por isso, evidente, que entre os mais importantes desafios colocados aos governos africanos no século xxi, estão:

1. Consolidar a legitimidade interna e cooperar activamente na construção do Estado-Nação (nation-building);

2. Reduzir a pobreza e a exclusão social;

3. Garantir a segurança e promover a confiança;

4. Equilibrar os custos e os benefícios da transformação para um desenvolvimento inclusivo e da integração nas áreas social, política, económica e institucional.

Para enfrentar estes desafios, parece imprescindível:

1. Melhor prevenção e gestão de conflitos;

2. Governação democrática e gestão transparente;

3. Tolerância para a diversidade política e cultural;

4. Respeito pelos direitos humanos;

5. Promoção do papel da mulher em todas as actividades;

6. Economias de mercado socialmente orientadas e responsáveis;

7. Legislação e instituições adequadas a um desenvolvimento de rosto humano;

8. Governabilidade e transparência, incluindo, códigos de conduta e declarações de património para os dirigentes a nível central, regional e local; fortalecimento dos serviços de inspecção; desempenho efectivo, com independência dos poderes políticos, da Alta Autoridade contra a corrupção, dos vários Tribunais e dos Comissários para a fiscalização dos direitos humanos.

\section{Nova parceria para o desenvolvimento susten- tado de África}

Os africanos têm consciência de que a mudança eficaz e eficiente da situação estrutural, que continua a impedir o desenvolvimento 
sistémico dos seus países, é uma necessidade inadiável: essa transformação não depende de uma «varinha mágica» vinda de fora do continente ou de um «milagre divino", mas sim do trabalho consciente e abnegado dos próprios povos e de seus líderes, unidos e coesos, na base dos mesmos ideais e interesses colectivos.

Para isso, a Nova Parceria para o Desenvolvimento de África (NEPAD), aprovada em 2001, em Lusaka (Zâmbia), pelos Estados-Membros da União Africana (UA), salienta três (3) grandes princípios como parâmetros fundamentais necessários à transformação da África:

1. O reconhecimento de que a boa governação é indispensável ao desenvolvimento da África;

2. A aceitação do desenvolvimento regional como a abordagem escolhida pelos estados africanos; e

3. A abertura da África ao capital privado.

Neste contexto, para a materialização destes princípios estratégicos, a NEPAD elege no seu programa, oito (8) áreas prioritárias, nomeadamente:

1. Desenvolvimento das infraestruturas em sentido lato;

2. Educação;

3. Saúde;

4. Agricultura;

5. Ambiente;

6. Novas tecnologias da informação e comunicação;

7. Energia;

8. Acesso aos mercados dos países desenvolvidos.

Entretanto, na visão do então presidente do Senegal Abdoulaye Wade (nascido em Maio de 1926), «conseguir capacidade nacional para satisfazer estes compromissos vai exigir reformas da administração e dos serviços públicos, forte supervisão parlamentar, tomada de decisão mais participativa a todos os níveis, medidas eficazes para combater a corrupção e uma reformajudicial completa [nos países africanos]» (WADE 2002: 86).

Evidentemente, apesar do grande potencial do continente africano - sendo considerado um pólo global - os desafios continuam a ser imensos e as responsabilidades dos seus líderes legítimos actuais e futuros - ainda maiores, se se quiser não só concretizar os 
objectivos-chave da NEPAD, mas também implementar a Agenda de Desenvolvimento Sustentável 2030, adoptada em Setembro de 2015, pela Organização das Nações Unidas (onU), assim como, os seus Objectivos de Desenvolvimento Sustentável (oDs) e Agenda 2063, aprovada no dia 31 de Janeiro de 2015, pela $24 .{ }^{\text {a }}$ Sessão Ordinária da Conferência dos Chefes de Estado e de Governo da União Africana (UA), em Addis Abeba, Etiópia, incluindo as sete (7) ambições africanas para a transformação estrutural e o desenvolvimento socioeconómico do continente (2015).

Com efeito, a Nova Agenda para o Desenvolvimento foi formalmente adoptada por 193 países, na Cimeira de Chefes de Estado e de Governo da onu, realizada em New York, Estados Unidos da América (EUA), entre 25 e 27 Setembro de 2015, no âmbito da 70. ${ }^{\text {a Sessão da }}$ Assembleia Geral daquela organização universal. Com a adopção desta nova agenda pós-2015, dever-se-á iniciar o processo da implementação da Agenda 2030 para o Desenvolvimento Sustentável.

A mesma agenda vigorará durante os próximos 15 anos e ditará, em larga medida, a definição das políticas para o desenvolvimento, assente em dezassete (17) Objectivos de Desenvolvimento Sustentável (oDs), sucessores dos Objectivos de Desenvolvimento do Milénio e respectivas metas e indicadores.

Em síntese, os obs pretendem promover e estimular acções em áreas críticas para a humanidade e para o planeta, nomeadamente:

- Erradicar a pobreza;

- Combater a fome e a insegurança alimentar;

- Garantir Saúde e bem-estar em todo mundo;

- Implantar Educação e formação escolar para todos;

- Garantir a igualdade de Géneros;

- Garantir Água e serviços sanitários como Direito Humano;

- Garantir Energia para todos;

- Garantir condições de trabalho mais justas para todos;

- Desenvolver infra-estruturas, industrialização e inovação sustentáveis;

- Garantir distribuição equitativa e redução das desigualdades;

- Estruturar Cidades nas quais se possa viver;

- Garantir consumo e produção sustentáveis;

- Combater as alterações climáticas;

- Proteger os Oceanos;

- Travar a destruição do meio ambiente; 
- Impôr a lei e a justiça; e

- Lutar por um futuro solidário. ${ }^{3}$

Com efeito, o objectivo 7 (SDG7), em particular, pretende assegurar o acesso a fontes de energia, em quantidade e em qualidade, de forma sustentável, para todos. Pretende, igualmente, garantir o acesso universal a serviços de energia, cada vez mais fiáveis e modernos, aumentar substancialmente a quota das energias renováveis no mix energético global e duplicar a taxa da eficiência energética até 2030.

Contudo, o desenvolvimento económico, a integração social e a protecção do meio ambiente, enquanto pilares do desenvolvimento sustentável, necessitam das Tecnologias de Informação e Comunicação (Tic) como catalisadoras desses objectivos. As Tics serão indispensáveis para alcançar os Objectivos de Desenvolvimento Sustentável. ${ }^{4}$

Nestas circunstâncias, a aplicação da visão estratégica preconizada pela NEPAD e a adesão dos países africanos ao Mecanismo Africano de Avaliação pelos Pares (APRM), podem ajudar a ultrapassar as distorções estruturais de que África padece, nomeadamente nos países envolvidos em conflitos ou em situação complexa de reconstrução pós-conflito. Neste contexto, a NEPAD e o APRM podem ser considerados marcos históricos na caminhada do continente africano para um futuro baseado no primado da lei, na governabilidade democrática e no desenvolvimento socio-económico, os quais têm provado ser, na prática, a melhor salvaguarda contra os conflitos, a discriminação, a desigualdade e a pobreza.

Um dos quatro (4) objectivos fundamentais para o sucesso da NEPAD e do APRM é a consolidação da ordem política constitucional na qual são assegurados a democracia, o respeito pelos direitos humanos, a lei e a ordem, a separação de poderes, bem como um responsável e eficaz sector público, de forma a promover um desenvolvimento sustentado e uma sociedade estável e pacífica.

3 Cf. Pedro Filipe «Conheça os 17 Objectivos de Desenvolvimento Sustentável das Nações Unidas», Portal Conexão Lusófona <http://www.conexaolusofona.org/ conheca-os-17-objetivos-de-desenvolvimento-sustentavel-das-nacoes-unidas/> (Consultado em 22 de Abril de 2017).

4 Cf. «Os 17 Objectivos de Desenvolvimento Sustentável: O papel das TICS», Portal Ciência <http://ciencia.ao/noticias/tecnologias/item/703-os-17-objectivos-de-desenvolvimento-sustentavel-o-papel-das-tics> (Consultado em 22 de Abril de 2017). 
Deste modo, e sustentando-nos na visão de Fátima Roque (2005) e em alguns estudos que produzi relativos à realidade de Angola (2013; 2014), para uma transformação sustentável no século XxI, objectivamos que África deve apostar em pelo menos quatro (4) vectores políticos fundamentais, e em seis (6) linhas socio-económicas estratégicas, bem assim como, no pilar de formação e valorização dos seus recursos humanos.

É por isso que, num exercício de síntese e de sistematização sempre incompletas, apontamos aqui os quatro (4) vectores proclamados em cima:

1. Construir um continente em paz e unido à volta de objectivos e valores comuns, o que implica promover uma democratização política e institucional que permite eleger governos eficientes, transparentes e responsáveis perante o eleitorado;

2. Garantir a justiça e proteger os direitos básicos e liberdades, incluindo a igualdade de oportunidades para todos e a capacitação/empoderamento (empowerment) dos mais desfavorecidos;

3. Promover o papel da mulher em todas as actividades;

4. Estabelecer a paz nacional, regional e continental, baseada na tolerância honesta da diversidade, bem como desenvolver uma visão humanista da sociedade e da política (RoQue 2005: 24, 29; BEMBE 2014: 199).

E, do ponto de vista económico e social, são estas, pelo menos, as sete (7) linhas estratégicas que África deve ter em conta, e sobretudo apostar, no decorrer do século xxI:

1. Conceber e aplicar uma estratégia política de desenvolvimento sustentado com justiça social a longo prazo.

2. Consolidar e fortalecer uma economia de mercado com forte investimento social e diversificação da oferta interna;

3. Assegurar a estabilidade macro-económica e promover um ambiente propício ao investimento privado nacional, regional e estrangeiro;

4. Promover um padrão equitativo de distribuição do rendimento e da riqueza, bem como de desenvolvimento nacional, regional e local;

5. Promover o crescimento equitativo e sustentado, bem como o desenvolvimento social, através de disciplina fiscal, desenvolvimento dos recursos humanos, investimento directo estrangeiro e redução da dívida externa; 
6. Reduzir progressivamente a incidência da pobreza e fome, da miséria e exclusão social;

7. Apostar na cooperação produtiva nacional, regional e internacional, por especialização, para facilitar uma participação mais efectiva na economia global (RoQue 2005: 29; BEMBE 2013: 172; 2014: 199).

Os aspectos acima elencados são fundamentais e por isso, inadiáveis. Com lucidez extraordinária, o sociólogo angolano Víctor Kajibanga insiste que o projecto democrático para África não deve ser reduzido às eleições multipartidárias, à proliferação de partidos políticos, e à liberdade de expressão e de imprensa. A «africanização» como processo de reapropriação do debate e dos valores da democracia pelos africanos deve ser um processo de desenvolvimento social, cultural e sustentável (KAJIBANGA 2009: 1, 6 e 7).

Nesta linha de pensamento, consideramos que o desenvolvimento, numa perspectiva antropossociológica, implica mudança social e cultural, tendo em conta que não pode ser reduzido a um fenómeno de carácter exclusivamente económico. A meta do desenvolvimento deverá ser equacionada numa perspectiva multidisciplinar, envolvendo a reorganização e a reorientação do sistema político, económico e social. Razão de sobra assiste a Heitor Barras Romana (1997), quando afirma que «os factores de progresso político relacionados com a credibilidade e consolidação das instituições do Estado são o suporte das estratégias de desenvolvimento socioeconómico» (apud (BEMBE 2014: 1992-1993).

Neste contexto e tentando adaptar a proposta de Nicolas Berggruen e Nathan Gardels, aposta na obra Governação inteligente para o século XXI, editada em 2013, afigura-se-nos que África e os governos africanos deveriam empenhar-se em caminhos de reforma definidos à escala doméstica, que conduzam à convergência e que contemplem as realidades culturais e estruturais em rápida mudança de cada Estado-Membro: reconciliando o nacional com o regional, o continental e o global (BERGgRUen e GaRdELS 2013: 225-224).

Por outro lado, e tal como sustentámos nos «Vectores da construção da Nação Angolana e a função de Estado», artigo editado em 2013 pela Mulemba - Revista Angolana de Ciências Sociais, órgão científico da Faculdade de Ciências Sociais (FCS) da Universidade Agostinho Neto (UAN), e na obra Mecanismos de partilha do poder e acomodação das Elites, editada em 2014 pelo Instituto Superior de Ciências Sociais e Políticas da Universidade de Lisboa, parece-nos 
ainda necessário priorizar o pilar relativo à «educação e formação», procurando valorizar os recursos humanos quer nos países africanos, quer ainda nas organizações sub-regionais e na própria organização pan-africana (União Africana).

A estratégia para a valorização dos recursos humanos encontra nos domínios da educação, da ciência e da investigação e desenvolvimento, um campo que se nos afigura de importância vital melhorar, tirando partido das qualidades intrínsecas dos povos africanos e dos meios disponíveis. Nesse desiderato:

1. Há que educar para preservar as identidades nacionais e o africanismo e, sob sua inspiração, estimular o desenvolvimento dos países africanos, em particular e do continente, em geral;

2. Há que fortalecer os sentimentos de pertença nacional e africana e os mecanismos de construção de uma cidadania livre e activa;

3. Há que formar, permanentemente, para dotar cada cidadão africano das ferramentas necessárias ao seu progresso individual e colectivo;

4. Há que inovar para conferir especificidade aos países africanos, incluindo o continente africano e torná-los mais competitivos, igualmente pela via da diferenciação (BЕMBE 2013: 172; 2014: 136-137).

A qualificação dos recursos humanos é, assim, uma aposta estratégica, que passa, inelutavelmente, por um modelo educacional flexível mas exigente e de formação de excelência. Só com recursos humanos qualificados e um sistema educativo exigente e eficaz, que não deixe ninguém de fora, é possível realizar, na prática, um verdadeiro Conceito Estratégico Nacional ou uma Estratégia Política Africana (duas questões fulcrais para Angola, que tratarei num próximo artigo para a Mulemba - Revista Angolana de Ciências Sociais), que traga esperança ao futuro dos africanos, através dos seus países, das diversas organizações regionais e sub-regionais africanas e da União Africana.

\section{Agenda 2063 da União Africana}

A Agenda 2063 é um plano endógeno de África para a sua transformação estrutural, através de um quadro estratégico comum que visa o crescimento inclusivo e o desenvolvimento sustentável dos 
estados-membros da União Africana (UA), em particular e do continente africano em geral. O processo de elaboração desta Agenda baseou-se no Acto Constitutivo da UA, na visão da União e da declaração solene de 2013 da Conferência da uA sobre o quinquagésimo aniversário $\left(50 .^{\circ}\right)$ da organização e nas sete (7) aspirações ou ambições africanas para 2063.

A Agenda apresenta, igualmente, um esquema director que estabelece as fases do seu desenvolvimento ou implementação nas diversas regionais e continente. Esta Agenda foi adoptada durante a 24. ${ }^{\mathrm{a}}$ Sessão ordinária da conferência dos Chefes de Estado e de Governo da União Africana, realizada em Addis Abeba, capital da República Federal Democrática da Etiópia, no dia 31 de Janeiro de 2015.

Como sublinha o Guia da União Africa 2017 (GUA 2017), os africanos defendem um continente próspero, em paz e segurança, conforme evidenciam as sete (7) aspirações para 2063:

1. Uma África próspera fundada no crescimento inclusivo e no desenvolvimento sustentável;

2. Um continente integrado, politicamente unido, guiado pelos princípios do pan-africanismo e pela visão do renascimento africano;

3. Uma África onde predomine a boa governação, os direitos do homem, a justiça e o Estado de direito;

4. Um continente em paz e segurança;

5. Uma África dotada de um património comum e uma identidade, de valores e ética culturais fortes;

6. Um continente onde o desenvolvimento esteja centrado nas populações, apoiando-se no potencial dos povos africanos, em particular das mulheres e da juventude, e que garanta sobretudo o bem-estar das crianças;

7. Uma África que se constitua como um actor e parceiro forte, unido e influente no plano mundial (GUA 2017: 15).

No âmbito do Primeiro Plano Decenal da Implementação (PDMO), ${ }^{5}$ para o período 2013-2023, a Agenda 2063 identificou treze (13) projectos ou fases prioritárias, para a sua materialização, nomeadamente:

5 Premier Plan Décennal de Mise en Euvre (PDMo). 
1. Uma rede ferroviária ntegrada de alta velocidade: com o objectivo de interligar todas as cidades capitais e pólos comerciais do continente;

2. A Universidade Pan-africana virtual: desenvolvida para acelerar o desenvolvimento do capital humano, da ciência, tecnologia e inovação;

3. Uma estratégia de comercialização dos produtos de base: visando disponibilizar aos países africanos os instrumentos necessários para o estabelecimento de um sector de matérias-primas dinâmico, que respeite os princípios de responsabilidade social e de meio ambiente sustentável;

4. Um fórum africano anual: para reunir os líderes políticos, o sector privado, a comunidade universitária e a sociedade civil de África, com vista a discussão e o debate da Agenda 2063;

5. A criação de uma Zona de Livre Comércio Continental (ZLEC) até 2017: com o objectivo de multiplicar por dois o comércio intra--africano até 2020, de falar a uma só voz nas negociações comerciais internacionais e estabelecer o Banco Africano de Investimento (2025), a Bolsa Pan-Africana dos Valores, o Fundo Monetário Africano (2023) e o Banco Centro-Africano (2028-2034);

6. O passaporte africano e a livre circulação de pessoas: pretende-se acelerar a integração continental ao facilitar a livre circulação de todos os cidadãos africanos no conjunto do continente até $2018 ;^{6}$

7. O projecto «fazer calar as armas até 2020 »: visa acabar com as guerras, conflitos e violações dos direitos humanos em África;

8. A barragem de Grande Inga (na República Democrática do Congo): para reforçar a produção energética no continente;

9. O Projecto pan-africano dos serviços em tempo real: visa transformar os aplicativos e serviços africanos em tempo real;

10. O projecto espacial africano: para reforçar o desenvolvimento africano nos diversos domínios, nomeadamente a agricultura, a gestão dos riscos de catástrofes naturais, a teledetecção, as

6 Com efeito, em 2016, alguns projectos acima referenciados conheceram alguns avanços, nomeadamente, o lançamento simbólico do passaporte africano, ocorrido por ocasião da $27 .^{\text {a }}$ Sessão Ordinária da Conferência dos Chefes de Estado e de Governo da União Africana (UA), realizada nos dias 17 e 18 de Julho de 2016, em Kigali, cidade capital da República do Rwanda, sob o lema: Ano africano dos Direitos Humanos com particular ênfase sobre os direitos das Mulheres. 
previsões climáticas, o sector bancário e financeiro, a segurança e defesa;

11. Um mercado de transporte aéreo africano: visa implementar um mercado único de transporte aéreo em África para estimular o desenvolvimento do transporte aéreo no continente;

12. Instituições financeiras continentais africanas: visam acelerar a integração do desenvolvimento socio-económico do continente. Estas instituições abrangem o Banco Central Africano; o Fundo Monetário Africano e o Banco Africano de Investimento;

13. Grande museu de África: situado em Alger, capital da República Argelina Democrática e Popular, o museu tornou-se um projecto emblemático desde o mês de Julho de 2016 (GUA 2017: 15-16).

\section{Considerações finais}

Para concluir, parece-nos importante sublinhar que África, enquanto continente, inclui os países africanos; estes, ao tomar consciência dos gigantescos desafios que os espera seja no contexto da NEPAD, da implementação da Agenda 2030 das Nações Unidas (sobretudo os 17 Objectivos de Desenvolvimento Sustentável), do Primeiro Plano Decenal de Implementação (2013-2023) estabelecido no âmbito da Agenda 2063 da União Africana e das próprias transformações causadas pelo fenómeno da globalização, devem encarar o futuro com determinação. Na sua essência, estes documentos são complementares e visam objectivos estratégicos comuns nos planos nacional, regional e continental e/ou mundial, e almejam a paz, a segurança, a estabilidade, a democracia e um desenvolvimento sustentável com rosto humano.

A mobilização de recursos é dos principais constrangimentos dos esforços para o desenvolvimento dos programas e a materialização dos objectivos definidos. Em relação a África, antes de pensar nas fontes externas (que poderão conduzir a aceitação da influência dos estranhos nalgumas decisões de carácter exclusivo), os países africanos devem fazer o máximo aproveitamento sustentável dos seus próprios recursos, numa coordenação de sinergias em volta de diversas parcerias.

Para Joaquim Chissano, antigo presidente da República de Moçambique, os «[recursos externos] devem ser um complemento a todo um esforço de mobilização das capacidades, caracterizada por 
uma alocação correcta em projectos de desenvolvimento e investimento dos parcos recursos financeiros provenientes da poupança interna» (CHISSANo 2012: 13).

Face à história africana recente, ligada à memória das lutas pela libertação nacional, aos constantes conflitos «intra» e «inter» estatais, às reconciliações fracassadas e às distorções estruturais existentes na economia e na sociedade, parece-nos avisado que o modelo de desenvolvimento a seguir em África na área social, deve assentar no respeito pelos direitos humanos, pela diversidade das culturas e religiões, pela educação e pelos múltiplos valores, princípios e sistemas de pensamento claramente evidenciados pelos povos. Esse modelo de desenvolvimento deve ter por base uma economia de mercado com forte componente social, sendo o poder público o garante da liberdade, da solidariedade e do interesse nacional e regional, sendo tudo isso posto ao serviço da construção de uma sociedade cada vez mais solidária para com os mais pobres, desprotegidos e excluídos.

A inclusão social e, necessariamente, a económica, deve ter o apoio e o contributo dos agentes políticos, dos empresários, dos investidores e das organizações cívicas e deve favorecer deliberadamente quem mais precisa.

Impõe-se, assim, a aplicação de uma agenda política, económica e socio-cultural de participação cívica activa e afirmativa, para que todos os africanos, quer nos seus países, quer nas instituições regionais e/ou continentais, se sintam parte integrante dessa sociedade solidária e dessa economia criativa. Como complemento, as populações africanas devem ter direito a afirmar a sua cultura e a sua identidade sem receio de sofrer represálias, antes com optimismo e orgulho.

Afinal, e na visão muito pertinente de Fátima Roque (2012: 10-11; 26-27), o futuro do continente africano constrói-se todos os dias e é, por isso, fundamental que os povos africanos sintam que podem ter, por um lado, confiança no Estado e nas suas instituições e, por outro, esperança numa melhoria significativa das condições de vida.

\section{Referências bibliográficas}

\section{Bembe Miguel Domingos}

2014, Mecanismos de partilha do poder e acomodação das elites. Modelo e processo para o Enclave de Cabinda. Lisboa, Instituto Superior de Ciências Sociais e Políticas da Universidade de Lisboa [«Estudos políticos e sociais»]. 
2013, «Os vectores da construção da nação angolana e a função do Estado", Mulemba - Revista Angolana de Ciências Sociais (Luanda), Luanda, Vol. III, n. ${ }^{\circ}$ 6, Novembro de 2013, pp. 167-183 .

BERGGRUEN Nicolas e GARDELS Nathan

2013 (1. ${ }^{\text {a }}$ edição), Governação inteligente para o século XXI. Uma via intermédia entre Ocidente e Oriente. Tradução de Érica Cunha e Bernardo de Sá Nogueira. Carnaxide, Editora Objectiva.

Chissano Joaquim

2002, "Prefácio: Paz, democracia e desenvolvimento no contexto da NEPAD", in Fátima Moura Roque, África, a NEPAD e o futuro. Luanda, Texto Editores.

FILIPE Filipe

«Conheça os 17 Objectivos de Desenvolvimento Sustentável das Nações Unidas», Portal Conexão Lusófona. Disponível em $<$ http://www.conexaolusofona.org/conheca-os-17-objetivos-de--desenvolvimento-sustentavel-das-nacoes-unidas $>$ (Consultado em 22 de Abril de 2017).

KAJIBANGA Víctor

2009, «Democracia e dimensão cultural de desenvolvimento. Uma reflexão sociológica sobre o caso africano», RAS - Revista Angolana de Sociologia (Luanda), n. ${ }^{\circ}$ 3, pp. 65-72.

PORTAL CIÊNCIA

«Os 17 Objectivos de Desenvolvimento Sustentável: O papel das TICs», Portal Ciência <http://ciencia.ao/noticias/tecnologias/ item/703-os-17-objectivos-de-desenvolvimento-sustentavel-o--papel-das-tics> (Consultado em 22 de Abril de 2017).

PORTAL CONEXÃo LUSÓFONA, ver FILIPE Pedro, supra

REzende Maria José

2008, «Las Naciones Unidas y la cuestion democrática hoy», $P o-$ lítica y Cultura (México), n. ${ }^{\circ}$ 30, Otoño, pp. 91-118 [Universidad Autónoma Metropolitana, Unidad Xochimilco].

Roque Fátima Moura

2012 (2. ${ }^{\mathrm{a}}$ edição), África, a NEPAD e o futuro. Luanda, Texto Editores.

RoQue Fátima Moura (Coord.)

2005, O desenvolvimento do continente africano na era da mundialização. Coimbra, Almedina.

WADE Abdoulaye 2002, «Governação democrática em África». Contribuição especial ao Capítulo 4-Democratizar a segurança para evitar o conflito e construir a paz, in Relatório do Desenvolvimento Humano: 
Aprofundar a democracia num mundo fragmentado. New York, PNUD - Programa das Nações Unidas para o Desenvolvimento; Lisboa, Mensagem - Serviço de Recursos Editoriais, Lda., p. 86. Disponível em: <https://pt.scribd.com/document/126654482/ RELATORIO-DESENVOLVIMENTO-HUMANO-PNUD-2002> tado em 22 de Abril de 2017).

\title{
Documentos
}

- Agenda de desenvolvimento sustentável 2030, incluindo os Objectivos de Desenvolvimento Sustentável. New York, United Nations, 2015.

- Agenda africana de transformação estrutural, crescimento inclusivo e desenvolvimento sustentável 2063. Addis Abeba, União Africana (UA), 2015.

- Guide de L'Union Africaine 2017 (Gua 2017). Ouvrage de référence pour le personel et les partenaires de l'Union Africaine. Coedição da Comissão da União Africana e Ministério dos Negócios Estrangeiros e do Comércio Exterior da Nova Zelândia.

- Mecanismo africano de avaliação pelos pares (APRM), Durban, União Africana (UA), Julho de 2002.

- Nova Parceria para o Desenvolvimento Sustentado de África (NEPAD), União Africana (UA), Lusaka, Julho de 2001.

\author{
Artigo solicitado ao Autor \\ Recepção do manuscrito: 8/12/2016 \\ Aceite para publicação: 30/12/2016
}

Title: The great challenges of African governments for the 21st century

Abstract: The governance system of many African countries is still characterized by a great dis-
respect for human rights, as well as the marginalization of the vast majority of their peoples. In
this context, Mbeki (2001), Mkapa (2001), Wade (2002), among others, consider that the struc-
tural and systemic transformation of Africa involves building more open, more democratic, more
transparent, more participatory and fair societies. However, Fatima Roque (2005; 2012) argues
that the success of Africa's transformation depends on overcoming the obstacles of extreme pov-
erty, social exclusion and illiteracy; Fragile social, political and military harmony; Corruption,
abuse of power and patronage; Weak political structures and underdeveloped civil societies; Dis-
crimination of gender, of classes and between the city and rural environment; Weakened infra-
structures; Lack of qualified professionals, specializations and motivations; Structural unemploy-
ment and too much dependence on the public sector; Unsustainable external debt and capital
account problems. Building on the New Partnership for Sustainable Development (NEPAD) (2001)
as well as the Sustainable Development Agenda (2030), including its Sustainable Development
Goals (2015), the Agenda 2063 of African Union, including the seven African ambitions for the 
continent's structural transformation (2015) and the African Peer Review Mechanism (APRM) (2002), this paper seeks to identify and characterize the vectors considered essential for African states to confront with security and success the multiple political, social and economic challenges posed to their governments in the 21st century.

Keywords: Africa, challenges, 2030 and 2063 agendas, NEPAD, sustained transformation, 21st century

\section{Miguel Domingos Bembe}

Polítologo e e especialista em Estratégia, é Doutor e Mestre em Ciências Sociais, na especialidade de Ciência Política (2014) e Estratégia (2009), respectivamente, pelo Instituto Superior de Ciências Sociais e Políticas (ISCSP) da Universidade de Lisboa (UL), em Portugal. É Professor Auxiliar no Departamento de Ciência Política (DCP) da Faculdade de Ciências Sociais (FCS) da Universidade Agostinho Neto (UAN), onde lecciona Análise Política I e II (Perspectivas Interna e Externa); Informações e Segurança; e Teoria e Prática da Democracia, sendo regente das disciplinas de Geopolítica e Geoestratégia; Políticas de Segurança e Defesa Nacional e Cultura Estratégica Angolana. É investigador do Centro de Investigação em Análise de Políticas e Sistemas Eleitorais (CIAPSE-FCS--UAN), em Luanda, e do Centro de Administração e Políticas Públicas (CAPP-ISCSP-UL), em Lisboa, Portugal. É Conselheiro do Quadro de Pessoal da Carreira Diplomática do Ministério das Relações Exteriores (MIREX) da República de Angola, exercendo as funções de Consultor no Gabinete do Ministro das Relações Exteriores (GMRE).

Os seus materiais fundamentais publicados são (livros): Da coexistência entre o Estado e o poder local em Angola. Interesses, conflitos, consensos. Prefácio de Fernando Paulo Faria. Luanda, Edições Mulemba; Ramada, Edições Pedago [ «Cadernos de Ciências Sociais - Série Ciência Política»; 2], 2016, 72p.; Mecanismos de partilha do poder e acomodação das elites. Modelo e processo para o Enclave de Cabinda. Com nota de abertura por Manuel Meirinho e prefácios de António de Sousa Lara e Heitor Barras Romana. Lisboa, Instituto Superior de Ciências Sociais e Políticas da Universidade de Lisboa [«Estudos políticos e sociais»], 2014; A questão de Cabinda: Uma visão estratégica. Evolução da situação e cenários de futuro. Prefácios de António de Sousa Lara e Armando Marques Guedes. Luanda, Edição do Autor, 2013; O terrorismo transnacional. Sistematização do fenómeno e estratégias para o seu combate. Prefácio de Mário Pinto de Andrade. Luanda, Edição do Autor, 2012; O estudo científico da Ciência Política. Abordagens epistemológicas e metodológicas. Luanda, Edições Mulemba; Ramada, Edições Pedago [«Cadernos de Ciências Sociais - Série Ciência Política»; 1], 2013 [em co-autoria com Paulo Faria e Fernando Muquepe]; (artigos): «Os grandes desafios dos governos africanos para o século xxI», Mulemba-Revista 
Angolana de Ciências Sociais (Luanda), vol. vi, n. ${ }^{0}$ 12, Novembro de 2016, pp.73-81; "A política externa angolana: Doutrina e prática», Mulemba - Revista Angolana de Ciências Sociais (Luanda), vol. vI, n. ${ }^{0}$ 11, Maio de 2016, pp. 25-55; «Participação política e cidadania em Angola», Mulemba - Revista Angolana de Ciências Sociais (Luanda), vol. v, n. ${ }^{\circ}$ 10, Novembro de 2015, pp. 471-492; «Partilha do poder no Enclave Angolano de Cabinda: Modelo e processo", Mulemba - Revista Angolana de Ciências Sociais (Luanda), vol. Iv, n. ${ }^{\circ}$ 8, Novembro de 2014, pp. 143-172; «Os problemas e debilidades de um continente à deriva: Para uma compreensão da geopolítica e estratégia africanas através de dois estrategistas africanos», Mulemba - Revista Angolana de Ciências Sociais (Luanda), vol. v, n. ${ }^{\circ}$ 10, Novembro de 2015, pp. 479-486; 2013, "Os vectores da construção da nação angolana e a função do Estado", Mulemba - Revista Angolana de Ciências Sociais (Luanda), vol. III, n. ${ }^{\circ}$ 6, Novembro, pp. 167-183; "Os vectores da construção da "Nação angolana" e a função do Estado", Mulemba - Revista Angolana de Ciências Sociais (Luanda), vol. III, n. ${ }^{\circ}$ 6, Novembro de 2013, pp. 167-183; «Poder local e democracia em Angola. Oportunidades e desafios», Mulemba - Revista Angolana de Ciências Sociais (Luanda), vol. II, n. ${ }^{\circ} 3$, Maio de 2012, pp. 35-57; "O Estado e o Poder Tradicional em Angola», Mulemba - Revista Angolana de Ciências Sociais, (Luanda), vol. I, n. ${ }^{\circ}$ 2, Outubro de 2011, pp. 9-27.

[e-mail: miguelbembe@fcs.uan.ao]

[e-mail: miguelbembe@gmail.com] 